\title{
A Two Channel Analog Front end Design AFE Design with Continuous Time $\sum-\Delta$ Modulator for ECG Signal
}

\author{
Mohammed Abdul Raheem ${ }^{1}$, K Manjunathachari ${ }^{2}$ \\ ${ }^{1}$ Department of Electronics and Communication Engineering, Muffakham Jah College of Engineering and Technology, \\ India \\ ${ }^{2}$ Department of Electronics and Communication Engineering, GITAM University, India
}

\begin{tabular}{l} 
Article Info \\
\hline Article history: \\
Received Mar 8, 2018 \\
Revised Jul 23, 2018 \\
Accepted Sep 2, 2018
\end{tabular}

\section{Keyword:}

Analog Front End Continuous Time (CT) Discrete Time (DT) Sigma Delta Modulator Signal Noise Ratio (SNR) SNDR

\begin{abstract}
In this context, the AFE with 2-channels is described, which has high impedance for low power application of bio-medical electrical activity. The challenge in obtaining accurate recordings of biomedical signals such as EEG/ECG to study the human body in research work. This paper is to propose Multi-Vt in AFE circuit design cascaded with CT modulator. The new architecture is anticipated with two dissimilar input signals filtered from 2-channel to one modulator. In this methodology, the amplifier is low powered multi-VT Analog Front-End which consumes less power by applying dual threshold voltage. Type -I category 2 channel signals of the first mode: 50 and $150 \mathrm{~Hz}$ amplified from AFE are given to 2nd CT sigmadelta ADC. Depict the SNR and SNDR as $63 \mathrm{~dB}$ and $60 \mathrm{~dB}$ respectively, consuming the power of $11 \mathrm{~mW}$. The design was simulated in a $0.18 \mathrm{um}$ standard UMC CMOS process at $1.8 \mathrm{~V}$ supply. The AFE measured frequency response from $50 \mathrm{~Hz}$ to $360 \mathrm{~Hz}$, depict the SNR and SNDR as $63 \mathrm{~dB}$ and $60 \mathrm{~dB}$ respectively, consuming the power of $11 \mathrm{~mW}$. The design was simulated in $0.18 \mathrm{~m}$ standard UMC CMOS process at $1.8 \mathrm{~V}$ supply. The AFE measured frequency response from $50 \mathrm{~Hz}$ to $360 \mathrm{~Hz}$, programmable gains from $52.6 \mathrm{~dB}$ to $72 \mathrm{~dB}$, input referred noise of $3.5 \mu \mathrm{V}$ in the amplifier bandwidth, NEF of 3 .
\end{abstract}

Copyright $($ C) 2018Institute of Advanced Engineering and Science. All rights reserved.

\section{Corresponding Author:}

M.A. Raheem,

Department of Electronics and Communication Engineering,

MJCET, Osmania University, Hyderabad, India.

Email: abdulraheem.mj@gmail.com

\section{INTRODUCTION}

ADVANCES in Complementary MOSFET technologies and low powered integrated circuits have stimulated considerable interests in wearable gadgets, anoccurrence which can potentially transfigure the healthcare devices. Sensor interface is the main part in the wearable gadgets, design of which should meet many uncompromising requirements both in digital block and in analog block. In designing AFE circuits, the corporal signals' nature is of much concern. The amplitude of these signals ranges from volts to $\mathrm{mV}$ and the frequencies vary from DC to a few kilo $\mathrm{Hz}$, as described in figure 1 [1]. The signals, the AFE should possess lowest input referred noise, reconfigurable bandwidth, and programmable gain to accommodate the weak signals and giant dynamic range. Furthermore, the skin-electrode interface instigates a high DC potential in an input signal that should be minimized by high pass filtration, cutting-off frequencies below $1 \mathrm{~Hz}$. While, such a high-pass filter with external capacitors and resistors can be easily implemented [2], it is further costeffective to integrate the filter on-chip. Switched-capacitor [3] are two possible approaches that could give good trade-offs between performance, power, and area as demonstrated in [4], [5]. It is noteworthy that an approach of pseudo-resistor not only diminishes the area but also ease reconfigurable design of band-pass filters [6]-[9]. A very high variation of resistances could be the drawback in existing pseudo-resistors which 
are tunable under negative and positive biased conditions. While working on low-voltage, it leads to a critical DC. In this, recognizing the programmable BE with reconfiguring amplifier the switch in four modes.

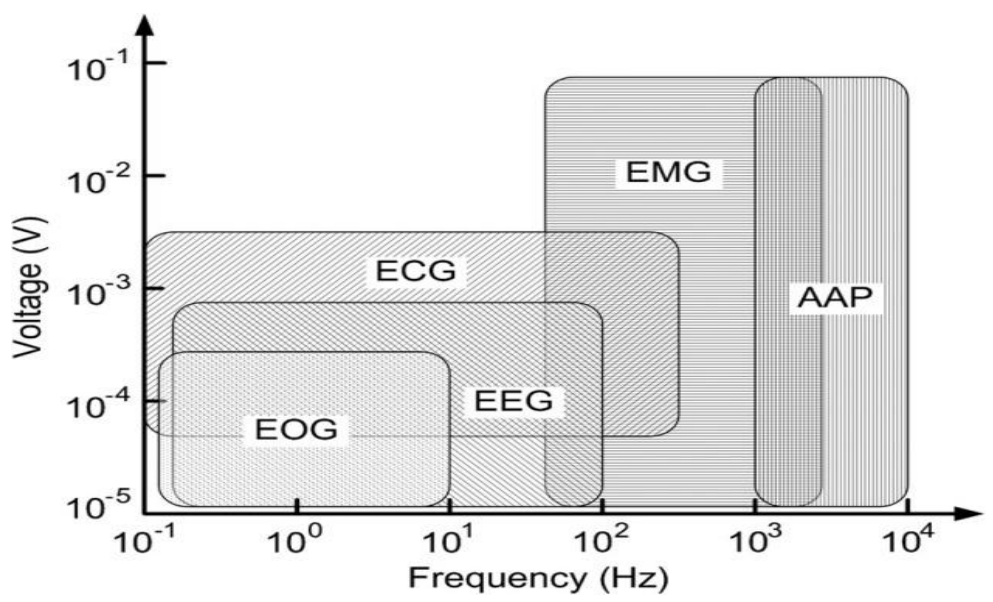

Figure 1. Voltage and frequency ranges of familiar physiological signals

Table 1. Medical Characteristics of the Familiar Physiology

\begin{tabular}{lll}
\hline Parameter & Signal Frequency & Standard Sensor \\
\hline Electroretinography (ERG) & $\mathrm{DC} \sim 50 \mathrm{~Hz}$ & Contact electrode \\
Electroencephalography (EEG) & $\mathrm{DC} \sim 150 \mathrm{~Hz}$ & Scalp electrode \\
Electrocardiography (ECG) & $0.01 \mathrm{~Hz} \sim 250 \mathrm{~Hz}$ & Skin electrode \\
Electroneurography (ENG) & $250 \mathrm{~Hz} \sim 5000 \mathrm{~Hz}$ & $\begin{array}{l}\text { Surface/needle } \\
\text { electrode }\end{array}$ \\
\hline
\end{tabular}

This paper is sectioned as described hereafter. Section-II depicts a Proposed System level architecture of AFE with Programmable Procedure. An AFE with sigma-delta modulator is delineated in Section III. Results from simulation and related thoughts are furnished in Section IV. Hence, the conclusions are derived under Section V.

\section{THE PROPOSED ARCHITECTURE 2- CHANNEL AFE FOR ECG SIGNAL MODULATOR}

This paper addresses a chip that comprises a low noise (TB-FEA), a programmable gain amplifier (PGA) and a 10-bit $\Sigma \Delta$ (SDM-ADC). The overall gain is programmed through the flip-over-capacitor feedback and proposed reconfiguring in the PGA. This allows the chip to offer FOUR operational modes, ERG, EEG, ECG, and ENG.

The microsystem for acquisition of bio-potential is as shown in figure 2. Bio-signals are amplified by AFE circuits and then they are converted into digital codes by ADCs [3]. In addition, analog multiplexers with large output current are designed to select the corresponding signals to ADCs. A trade-off in the microsystem exists between power and the area. The ratio between count of AFEs and ADCs affects the inclusivefunctioning. 

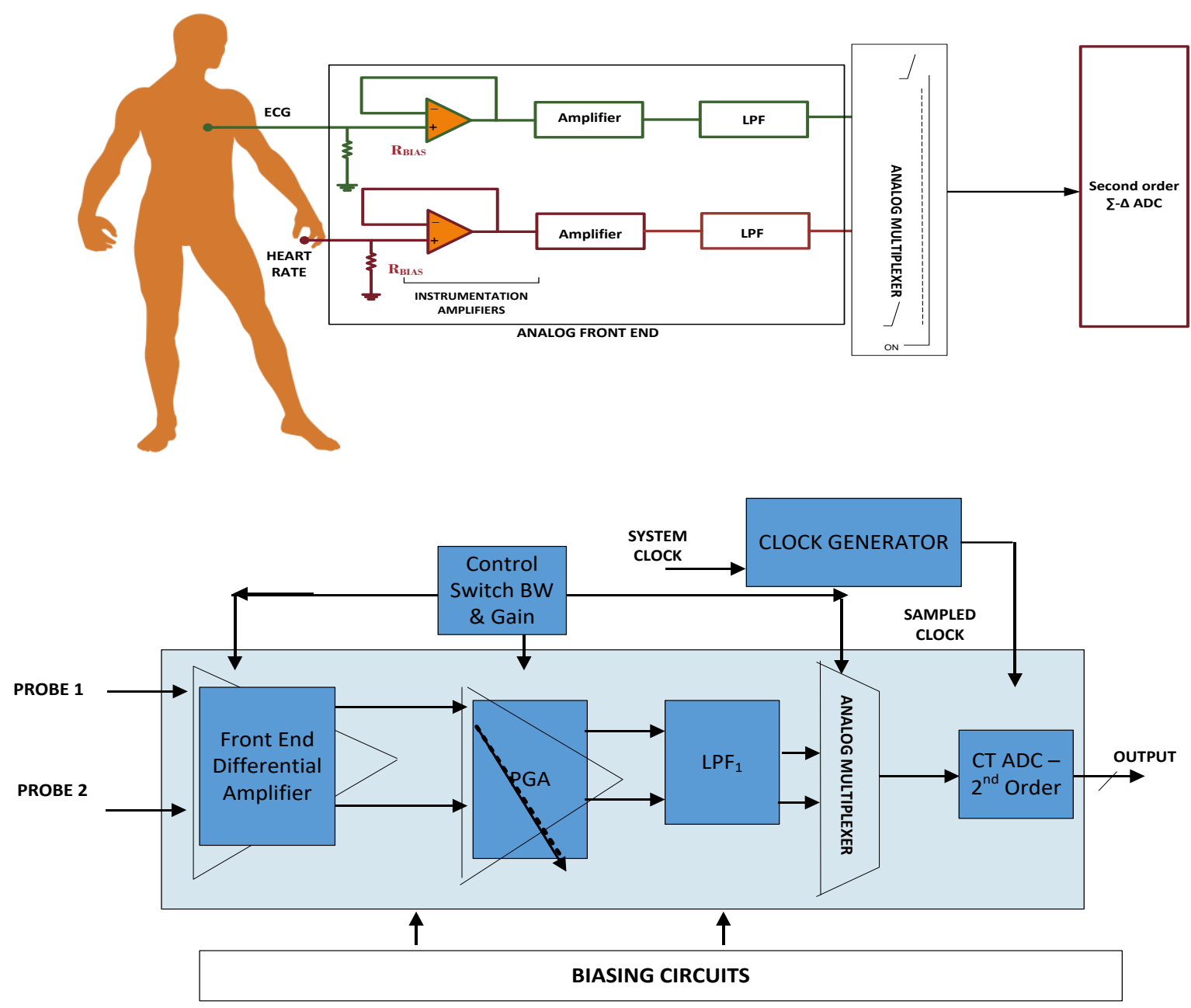

Figure 2. Proposed architecture of 2 channel

\subsection{Noise Contribution at AFE design}

The Flicker Noise 1/f reduction always remains a challenge in the bio-signal acquisition. This problem cannot be avoided completely 1/f noise exist in all the devices of MOSFET due to their surface conduction mechanism. For a MOS working in saturation region the total flicker noise power spectrum could be calculated as

$$
\begin{aligned}
& \mathrm{g}_{\mathrm{m}}=\sqrt{2 \cdot \mathrm{m}_{\mathrm{eff}} \cdot \operatorname{Cox} \cdot \frac{\mathrm{W}}{\mathrm{L}} \cdot \mathrm{I}_{\mathrm{ds}}} \\
& \mathrm{i}_{\mathrm{f}}^{2}=\mathrm{a}_{1} \cdot \frac{\mathrm{q} \cdot \mathrm{m}_{\mathrm{f} \cdot(\mathrm{vgs}-\mathrm{Vt}) \cdot \mathrm{Ids}}}{\mathrm{L}^{2} \cdot \mathrm{f}}
\end{aligned}
$$

The spectral density for a MOSFET is given from [9] as:

$$
\mathrm{v}_{\mathrm{f}}{ }^{2} \underbrace{4 \mathrm{kT} \frac{2}{3} \frac{1}{\mathrm{~g}_{\mathrm{m}}}}_{\text {Thermal }}+\underbrace{\frac{\mathrm{K}_{\mathrm{f}}}{\mathrm{WLC}_{\mathrm{ox}} \mathrm{f}}}_{\text {Flicker }}
$$




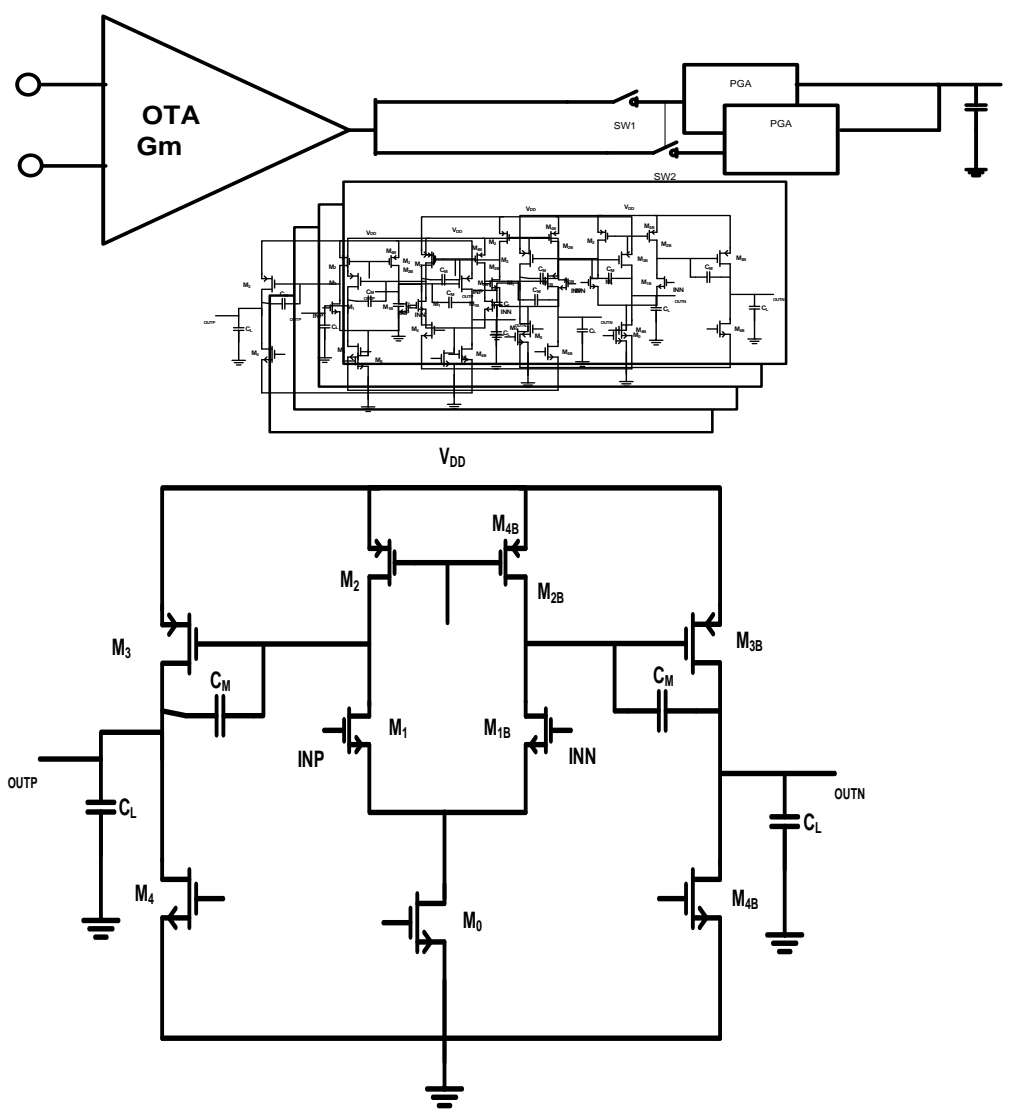

Figure 3. (a) Proposed Block diagram of Programmable two 2 control switches (b) Two-stage load compensated OTA

\subsection{A Tunable Bandwidth Low Noise Amplifier in AFE}

In the above Figure 2 the entire AFE design for biomedical LNA. The load-compensated amplifier of two-stage was chosen amongst the, OTA due to its power-efficiency, minimum load capacitance and rail to rail output swing for an optimum phase margin and GBW. Figure 3 depicts the two-stage amplifier along with load-compensation.

$$
\begin{aligned}
& \mathrm{A}_{0}=g_{\mathrm{m} 1} \mathrm{R}_{\text {out } 1} \times g_{\mathrm{m} 5} R_{\text {out } 2} \\
& \mathrm{GBW}=\frac{\mathrm{g}_{\mathrm{m} 1} \cdot \mathrm{g}_{\mathrm{m} 5} \cdot \mathrm{R}_{\text {out } 1}}{2 \pi \mathrm{C}_{\mathrm{L}}}
\end{aligned}
$$

Where $\mathrm{g}_{\mathrm{mi}}$ is the transconductance of the $\mathrm{i}^{\text {th }}$ transistor, $\mathrm{R}_{\text {outi }}$ is the output resistance of tenth stage of the OTA. Furthermore it is assumed, all the transistors would work under the saturation region. From Eq. (3), we observe, thermal noise contribution is proportional inversely to transconductance gm. From the EKV model the transconductance normalized with respect to drain current.

$$
\frac{\mathrm{g}_{\mathrm{m}, \text { Strong }}}{\mathrm{I}_{\mathrm{Ds}}}=\frac{12}{\mathrm{~V}_{\mathrm{eff}}}
$$

Hence by increasing the drain current $\mathrm{I}_{\mathrm{ds}}$ and biasing the MOSFET in the weak inversion region of operation the thermal noise suppression is maximized. The most of noise contribution will come from the input signal of the first stage of the amplifier.

\begin{tabular}{ll}
\hline Control Switch & Parameter \\
\hline 0 & ECG Signal (Heart) \\
1 & Heart Rate (Index Finger) \\
\hline
\end{tabular}




\subsection{Modulator Circuit}

The device sizing W/L of input pair should be large to optimize the noise level at input. The OTA which acts as the key component in the modulator is used by the integrator and must possess high gain for smooth integration. The general two-stage amplifier consists of the single-ended differential amplifier having high gain, biasing circuit, compensation circuit and the second gain stage, as shown in the Figure 4 . The basic OTA architecture includes a differential amplifier which has high gain with dominant pole. The second stage employs a common source amplifier. A unity follower with high frequency is used in the third stage. The differential amplifier is usually used as the first stage in amplifier with differential input and single ended output. The second stage is the most desirable stage for a high output swing and it also increases the gain. Although the gain increases, the bandwidth reduces and hence the designers would have to decide in this trade-off. To maintain the stability of the amplifier when negative feedback is given, the Compensation Circuit is employed.

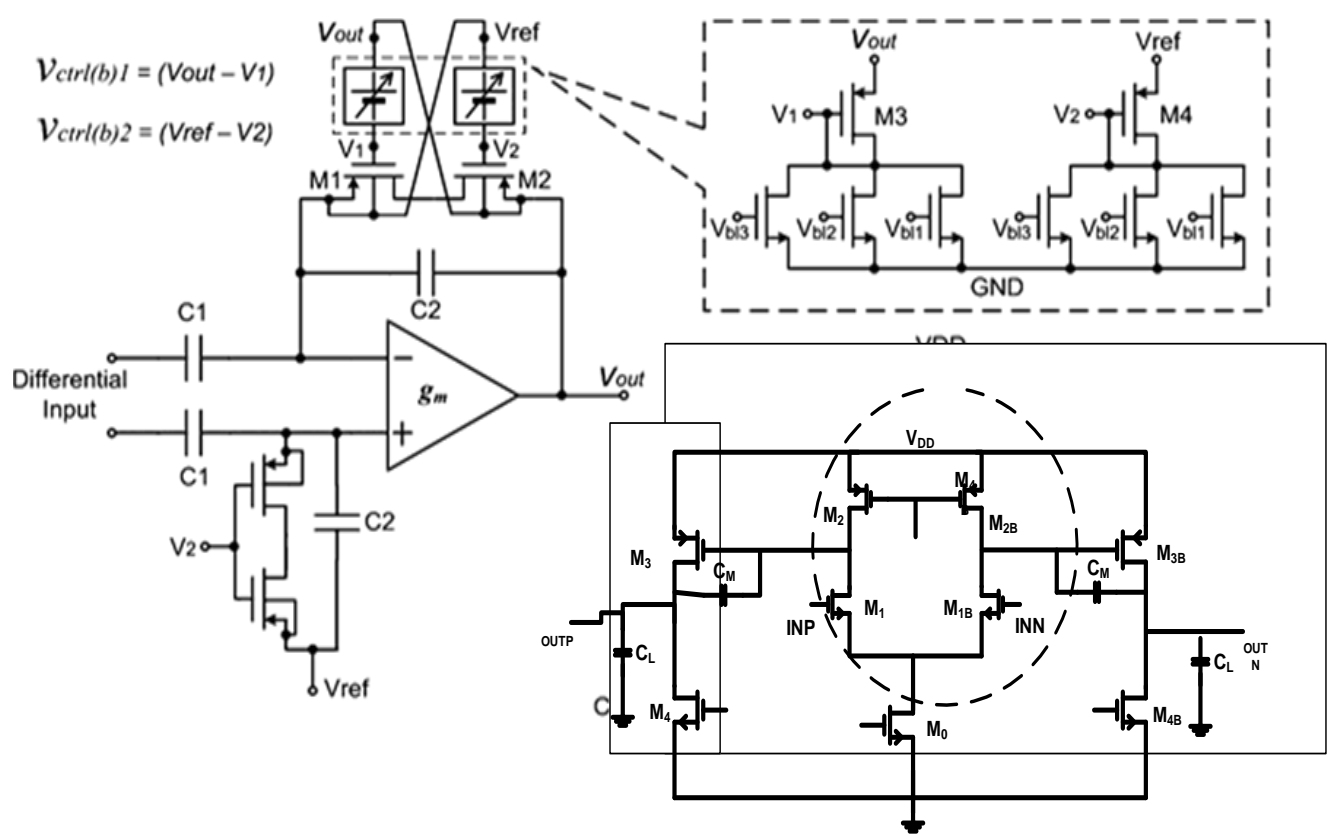

Figure 4. Schematic of Tunable Bandwidth with balanced pseudo-resistor replicas

In this circuit, the load-compensation technique is second-hand which is distinct as the compensation in which the compensator act on the output signal after it had generated feedback signals. The load-compensation is conceded using a $\mathrm{Cc}$ and Common-mode Feedback (CMFB) system. Preliminary transients in the output occur due to the time is taken by the CMFB circuit to be effective and to bring the common mode DC output to the desired voltage, halfway sandwiched between the supply rails in this case. The gain of the OTA was originated to be $72 \mathrm{~dB}$ and the UGB for this configuration was $25 \mathrm{KHz}$. The phase margin measured is $73^{\circ}$. In the schematic of OTA, as shown in Figure 4, the bottom circuit that consists of transmission-gate switches is CMFB circuit, whereas; the two-stage OTA is the CMOS circuitry above feedback system.

\section{DISCUSSION OF RESULTS}

The proposed architecture is Instrumental analysis with practical simulation on $0.18 \mu \mathrm{m}$ UMC CMOS technology the results are observed as shown in the above respective figures. The input impedance has great value $(>100 \mathrm{G} \Omega)$ ECG lies on $(3 \mathrm{~Hz}-10 \mathrm{~Hz})$. The input voltage is $10 \mathrm{~m}$ to $100 \mathrm{mV}$ is amplified with chopping technique, further amplified with multi-VT technique, the power consumption of this AFE Instrumental amplifier is depicted in the Pie chart. 


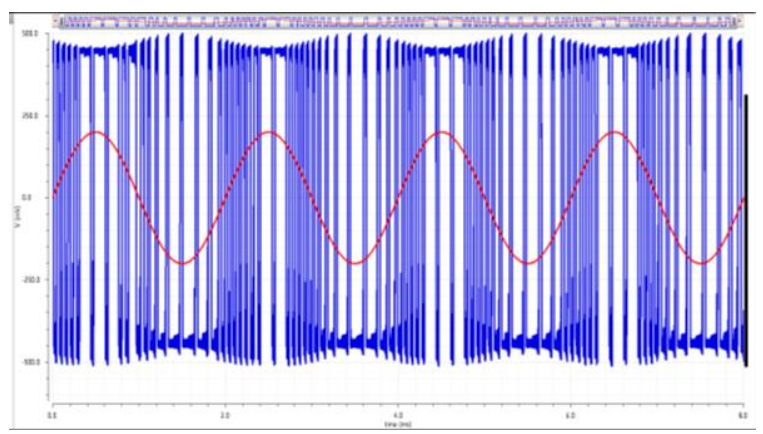

Figure 8. Transient Analysis of signal of $0.2 \mathrm{~V}$ and frequency of $500 \mathrm{~Hz}$ modulator

Table II. Performance of two different Modulators

\begin{tabular}{ccc}
\hline Parameter & Mode A & Mode B \\
\hline Technology & \multicolumn{2}{c}{$0.18 \mu \mathrm{m}$ CMOS } \\
Supply Voltage & \multicolumn{2}{c}{$1 \mathrm{~V}$} \\
Sampling Frequency & $64 \mathrm{kHz}$ & $32 \mathrm{kHz}$ \\
Signal Bandwidth & $250 \mathrm{~Hz}$ & $50 \mathrm{~Hz}$ \\
Oversampling ratio & 128 & 320 \\
Peak SNR & $63 \mathrm{~dB}$ & $85 \mathrm{~dB}$ \\
Dynamic Range & $58.5 \mathrm{~dB}$ & $73 \mathrm{~dB}$ \\
Power Consumption & $990 \mathrm{nW}$ & $685 \mathrm{nW}$ \\
FOM pJ/step & .175 & 0.878 \\
FOM & 137.43 & 129.20 \\
\hline
\end{tabular}

The gain is $52.6 \mathrm{~dB}$ and $72 \mathrm{~dB}$. An output noise of Low Noise AFE is simulated with QPSS is shown in Figure 6. The SNR measured SNR, SNDR, and ENOB of whole design with four different modes of 2 nd order CT $\Sigma$ - $\Delta$ modulator) ADC resolution and dynamic range requirements are shown in the Figure 7 and Figure 5. Table III compares the achieved design performance with recent prior art. Conventionally, NEF is used for comparison.

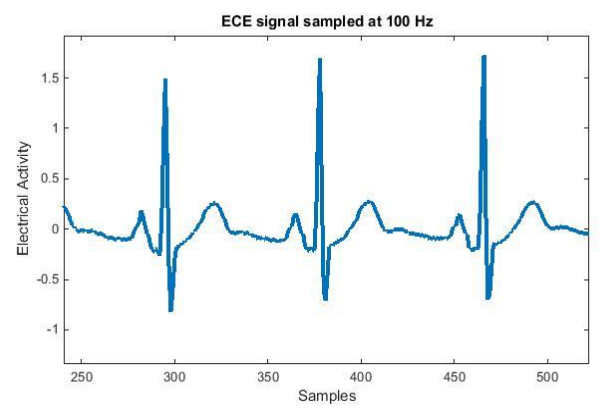

Figure 5. The ECG signal sample at $100 \mathrm{~Hz}$

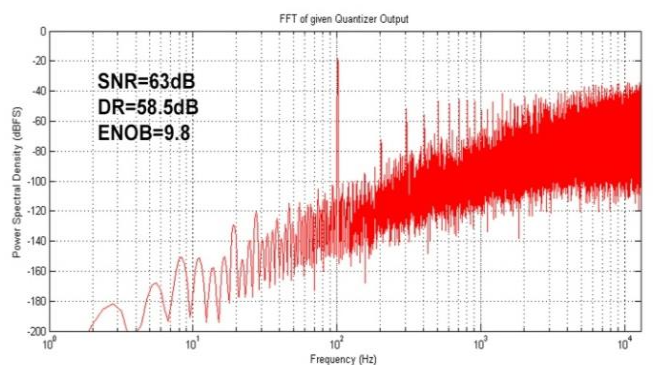

MOD-I: Measured at 16384 point output spectra (BW:100Hz, DR:58.5dB, Fs=64KHz)

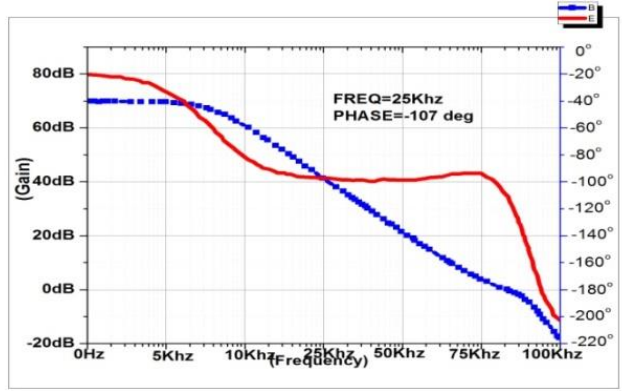

Figure 6. Gain and Phase Margin of an amplifier

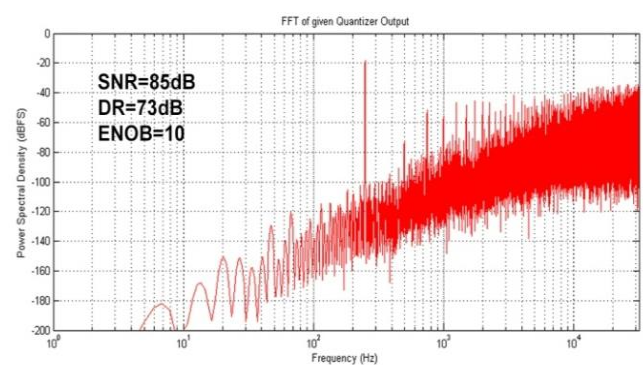

MOD-II: Measured at 16384 point output spectra (BW:250Hz, DR:85dB, Fs=32KHz)

Figure 7. SNR Plots 


$$
\mathrm{NEF}=\mathrm{Vrms}, \text { in } \sqrt{\frac{2 \mathrm{I} \text { total }}{\pi \mathrm{V}_{\mathrm{t}} \cdot 4 \mathrm{kT} \cdot \text { Bandwidth }}}
$$

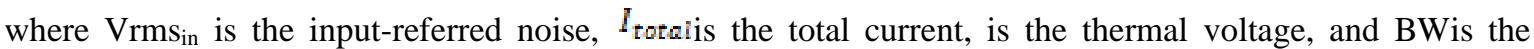
bandwidth of the AFE with chopping technique.Usually AFE circuits attain a NEF of 2.5 to 10 . The complete layout design with IO pad of the 2 channel AFE with modulator is shown in Figure 8 . The Area occupied by the filter is $209.41 \mu \mathrm{m} \times 80.21 \mu \mathrm{m}=0.0167 \mathrm{~mm}^{2}$.

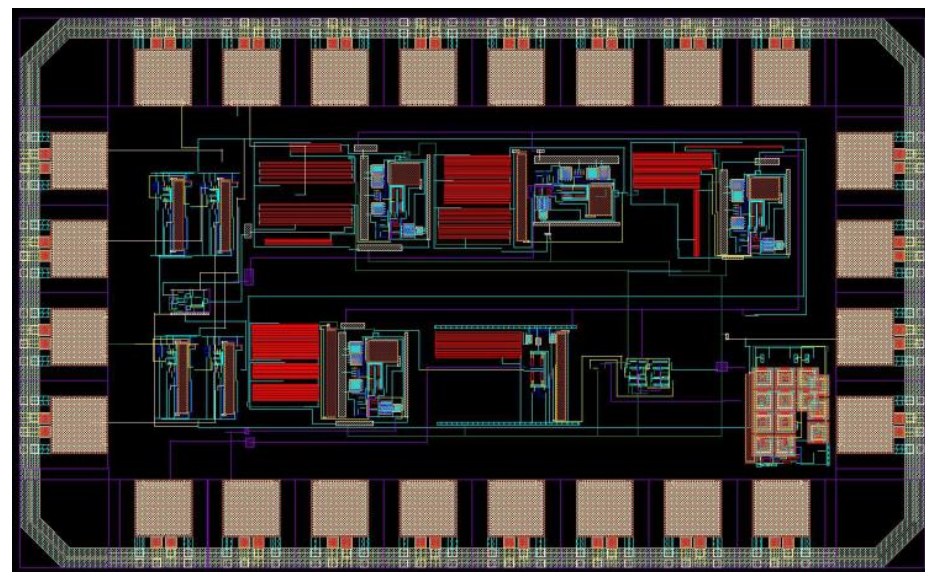

Figure 8. Final Layout of AFE with Dual Sigma-Delta Modulator

Power role of the different blocks is shown in Figure 9. As seen in Figure, more than half of the power budget is dedicated to the different mode of 2 nd order CT $\Sigma-\Delta$ modulator. The chopping switch and clock generator are consumed more power when compared to amplifier due to noise considerations.

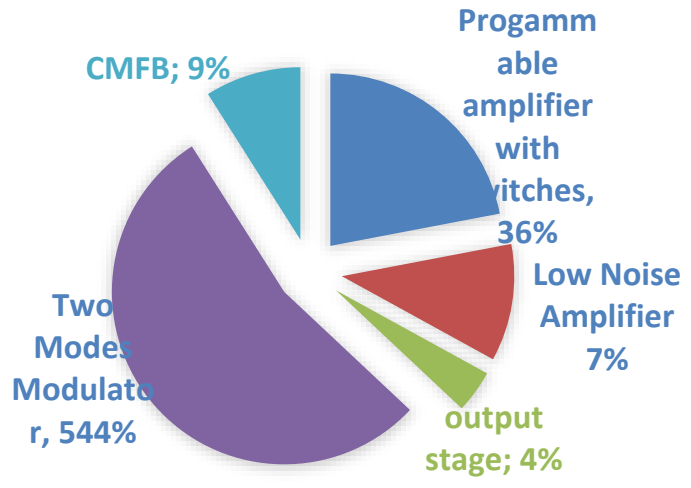

Figure 9. Power Consumption and distribution in Pie chart of whole design

Table III. Comparison of PRIOR ART

\begin{tabular}{cccccc}
\hline Parameter & {$[7]$} & {$[8]$} & {$[9]$} & {$[11]$} & This Work \\
\hline Tech. $(\mu \mathrm{m})$ & 0.5 & 0.18 & 0.8 & 0.13 & 0.18 \\
Supply $(\mathrm{V})$ & 2.8 & 1.5 & 1.8 & 1.2 & 1 \\
Bias $(\mathrm{nA})$ & 743 & 5000 & 1050 & $580^{\mathrm{a}} / 902^{\mathrm{b}}$ & 500 \\
Gain $(\mathrm{dB})$ & 40.9 & 40.8 & $41-50.5$ & $40-83$ & $52.8-72$ \\
Input Ref.Noise $(\mu$ Vrms $)$ & 1.66 & 1.27 & 0.98 & 2.06 & 3.5 \\
HPF $(\mathrm{Hz})$ & 0.4 & 0.5 & $0.05-0.4$ & 0.17 & 0.1 \\
LPF $(\mathrm{KHz})$ & $0.045-5.3$ & $0.1-0.4$ & 0.120 & $0.34-7.5$ & 7.0 \\
NEF & 3.21 & 6.1 & $4.6-5.4$ & $3.28^{\mathrm{a}} / 4.1^{\mathrm{b}}$ & 3.04 \\
\hline
\end{tabular}




\section{CONCLUSION}

In this paper, a 2-channel ECG amplifier with appropriate features for dry and non-contact biopotential applications is presented. Unable to compare the complete design with other design this paper proposed the architectural system level design which is suitable for biomedical application targeted to ECG for $10 \mathrm{mV}$ to $100 \mathrm{mV}$. Especially, in this paper the multi-VT concept is implemented in the circuit level which reduces the power consumption and the gain achieved by amplifier $52.9 \mathrm{~dB}$ and $72 \mathrm{~dB}$ with an NEF 3.0 , noise performance is satisfactory. Furthermore, another important approach the two different 2 nd order CT $\Sigma$ - $\Delta$ modulator to improve the performance.

\section{ACKNOWLEDGEMENTS}

The authors would like to express their great appreciations and gratitude to Muffakham Jah College of Engineering and Technology for providing research facilities, technical support, and research environment.

\section{REFERENCES}

[1] Y.M. Chi, Y.T. Wang, Y. Wang, Ch. Maier, T.P. Jung, and G. Cauwenberghs, "Dry and non-contact EEG sensors for mobile brain-computer interfaces", IEEE Transactions on Neural Systems and Rehabilitation Engineering, vol. 20, no. 2, March 2012

[2] M. Steffen, A. Aleksandrowicz, and S. Leonhardt, "Mobile noncontact monitoring of heart and lung activity", IEEE Transactionson Biomedical Circuits and Systems, vol. 1, no. 4, pp. 250-257, Dec. 2007.

[3] J. Kranjec, S. Beguš, J. Drnovšek, and G. Geršak, "Novel methods for non-contact heart rate measurement: A feasibility study", IEEE Transactions on Instrumentation and Measurement, vol. 63, no. 4, April 2014

[4] Y.G. Lim, K.K. Kim, and K.S. Park, "ECG recording on a bed during sleep without direct skin-contact", IEEE Transactions on Biomedical Engineering, vol. 54, pp. 718-725, 2007.

[5] S. Leonhardt, and A. Aleksandrowicz, "Non-contact ECG monitoring for automotive application", 5th International Summer Schooland Symposium on Medical Devices and Biosensors, ISSS-MDBS, June 2008, pp. 183185.

[6] X.X. Chen, Y. Lv, R.R. Zhen Fang, Sh. H. Xia, and H. Li, Li. Tian,“A wireless non-contact ECG detection system based on capacitive coupling", IEEE 14th International Conference on e-Health Network.

[7] W. Wattanapanitch, et al., "An energy-efficient micropower neural recording amplifier", IEEE Trans. on Biomedical Circuits and Systems, vol. 1, pp. 136-147, June 2007.

[8] S. Kao, et al., "A $1.5 \mathrm{~V} 7.5 \mu \mathrm{W}$ programmable gain amplifier for multiple biomedical signal acquisition", IEEE Biomedical Circuits and Systems Conference, 2009, pp. 73-76.

[9] T. Denison, et al., "A $2 \mu \mathrm{W} 100 \mathrm{nV} / \mathrm{rt} \mathrm{Hz}$ chopper-stabilized instrumentation amplifier for chronic measurement of neural field potentials", IEEE J. of Solid-State Circuits, vol. 42, pp. 2934-2945, Dec. 2007.

[10] T. Yoshida,et al., "A high-linearity low-noise amplifier with variable bandwidth for neural recording systems", Japanese J. of Applied Physics, vol. 50, pp. 1-4, April 2011.

[11] Christopher J. Mandic, DebashishGangopadhyay and David J. Alls, “ A 1.1 $\mu$ W 2.1 $\mu$ VRMS Input Noise Chopperstabilized Amplifier for Bio-medical Applications", Circuits and Systems (ISCAS), 2012 IEEE International Symposium on 20-23 May 2012, Seoul, South Korea

[12] Y.M. Chi, T.P. Jung, and G. Cauwenberghs, "Dry-contact and noncontactbiopotential electrodes: methodological review", IEEE Reviews in Biomedical Engineering, vol. 3, 2010

[13] Y. Ch. Chen, B. Sh. Lin, and J. Sh. Pan, "Novel non-contact dry electrode withanadaptive mechanical design for measuring EEG in ahairy site", IEEE Transactions on Instrumentation and Measurement, vol. 64, no. 12, pp. 3361 -3368, Dec. 2015.

[14] Y.M. Chi, Ch. Maier, and G. Cauwenberghs, "Ultra-high input impedance, low noise integrated amplifier for noncontact biopotential sensing", IEEE Journal on Emerging and Selected Topics in Circuitsand Systems, vol. 1, no. 4, Dec. 2011.

[15] F. Rummens, S. Renaud and N. Lewis, "CMOS differential neural amplifier with high input impedance", The 13th IEEE International NEW Circuits and Systems (NEWCAS) conference, June 2015, pp. 1-4.

[16] P. Monsurro, S. Pennisi, G. Scotti, and A. Trifiletti, "Inverting closed loop amplifier architecture with reduced gain error and high input impedance", IEEE International Symposium on Circuits and Systems (ISCAS), May 2006.

[17] N. Verma, A. Shoeb, J. Bohorquez, J. Dawson, J. Guttag, and A. P.Chandrakasan, "A micro-power EEG acquisition SoC with integrated feature extraction processor for a chronic seizure detection system", IEEE J. SolidState Circuits, vol. 45, no. 4, pp. 804-816, Apr. 2010.

[18] L. Fay, V. Misra, and R. Sarpeshkar, "A micropower electrocardiogram amplifier", IEEE Transaction Biomedical Circuitand System, vol. 3, no. 5, Oct. 2009.

[19] S. Ha et al., "Integrated circuits and electrode interfaces for Noninvasive physiological monitoring", IEEE Transactions on Biomedical Engineering, vol. 61, no. 5, pp. 1522-1537, May 2014.

[20] H.F. Achigui, M. Sawan, C.J.B. Fayomi, "A 1 V Low Power, Low Noise DTMOS based NIRS Front-End Receiver", in Proc. WMSCI, Jully 2005. 
[21] Qu Ruoyuan, Li Tong, Li Xiao, XuMinglu, Chen Yueyang, Wang Xinghua, "Wireless Neural Acquisition System Design", $201335^{\text {th }}$ Annual International Conference of the IEEE Engineering in Medicine and Biology Society.

[22] A. FazliYeknami and A. Alvandpour, "A 0.5-V 250-NW 65-dB SNDR Passive $\Delta \Sigma$ Modulator for Medical Implant Devices", in Proc. IEEE InternationalSym.Circuits and Systems, May 2013, pp. 2010-2013.

[23] M.A. Raheem, K. Manjunathaachari, and Arifuddinsohel. "A Design of $2^{\text {nd }}$ Order DT Sigma-Delta Modulator for Medical Implants”, in Proc. IEEE PrimeAsia, Dec 2015,978-1-5090-0136-1/15/\$31.00 @2015 IEEE

[24] M.A. Raheem, K. Manjunathaachari, "presented as paper presentation IEEE paper "A Logarithmic DWA based Discrete Time MultibitSigma-DeltaModulator", IEEE sponsored conference INBUSH ERA 2015. ISBN:978-14799-8432-9 at Amity University Greater Noida Feb25 -27 2015”

[25] M.A. Raheem, Mohammed Arifuddin Sohel and Maliha Naaz "Design of Discrete-Time Notch Filter for Biomedical Applications", in Conference Proc. IEEE Device of Integrated Circuits DevIC 2017 10.1109/DEVIC 2017.8073997

[26] Maizan Muhamad, NorhayatiSoin and Harikrishna Ramiah "Design of Low power Low Noise Amplifier using Gm- boosted Technique", in Indonesian Journal of Electrical Engineering and Computer Science ISSN: $2502-$ 4752, DOI: 10.11591/ijeecs. v9. i3. pp685-689

[27] M.A. Raheem, Mohammed Arifuddin Sohel and Maliha Naaz "Design of Discrete-Time Notch Filter for Biomedical Applications", in International Journal of Innovative Research in Electrical, Electronics, Instrumentation, and control Engineering, Vol 4 issue 12, December 2016

[28] Ahmed Al-Hashimi, Anis Nurashikin Nordin*, Amelia Wong Azman, "Design of a Reconfigurable, Modular and Multi-Channel Bioimpedance Spectroscopy System", in Indonesian Journal of Electrical Engineering and Computer Science, DOI: 10.11591/ijeecs. v8. i2. pp428-440

[29] M.A. Raheem, Mohammed Arifuddin Sohel and Maliha Naaz, "Quad Mode of Sixteen-Channel Chopper AFE Design and Cascaded with Continuous Time $\sum-\Delta$ Modulator for Electroencephalogy Monitory System", in International Journal of Simulation, Systems, Science and Technology ISSN 1473-8031Research in Electrical, Electronics, Instrumentation and control Engineering, Vol 8 Number 3, September 2017

[30] A. AAmin, M.S. Islam, M.A. Masud, M.N.H. Khan, "Design and Performance Analysis of 1.8 GHz Low Noise Amplifier for Wireless Receiver Application", in Indonesian Journal of Electrical Engineering and Computer Science DOI: 10.11591/ijeecs. v6. i3. pp656-662

\section{BIOGRAPHIES OF AUTHORS}

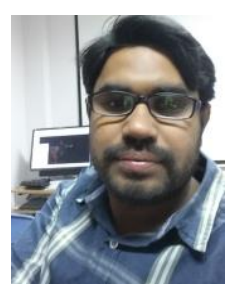

Abdul Raheem is a research scholar from Hyderabad, Telangana, India. He has completed id Bachelors in Engineering in 2005, and Masters in VLSI System Design from GRIET, JNTU Hyderabad, currently doing P.hD at Gitam University As a research Scholar in Micro-electronics in Analog \& amplifiers; Mixed Signal, Hyderabad, India. His Current research mainly focuses on CMOS Analog- Mixed signal Integrated Circuits. His current focus to design Low power architectures for biomedical application. His ongoing work design are focus to Analog Front Design, low power design of Sigma Delta Modulator and bandgap reference circuits. He is expert in IC EDA tools interfacing with Specification to GDSII. He has presented a papers 21 National and International IEEE Conference. He also received best paper award in IEEE Conference of Post Graduate Research in Micro-Electronics ASIA (PRIME ASIA 2015)

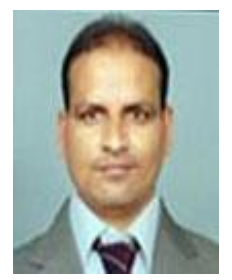

K Manjuanthachari is currently a professor and Head of the Electronic \& Communication Engineering Department at Gitam University Hyderabad Telangana, and his research in Signal Processing and Image Processing, MPEG, with Interfacing with FPGA, He has enormous experience in teaching and industry, he is guiding the 12 research scholar at Gitam University. He has 50 plus publications in National and International Journal /Conferences. 